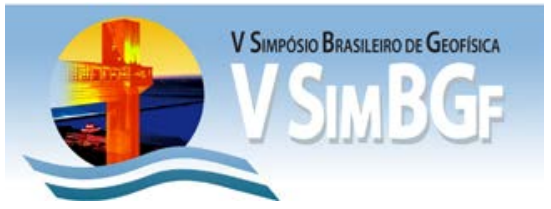

\title{
O impacto da porosidade na avaliação da impedância acústica em meios poroelásticos.
}

José Sampaio de Oliveira, Observatório Nacional.

Jorge Leonardo Martins, Observatório Nacional.

Copyright 2012, SBGf - Sociedade Brasileira de Geofísica

Este texto foi preparado para a apresentação no V Simpósio Brasileiro de Geofísica, Salvador, 27 a 29 de novembro de 2012. Seu conteúdo foi revisado pelo Comitê Técnico do V SimBGf mas não necessariamente representa a opinião da SBGf ou de seus associados. É proibida a reprodução total ou parcial deste material para propósitos comerciais sem prévia autorização da SBGf

\section{Resumo}

Melhorar a precisão dos métodos geofísicos aplicados na pela indústria da exploração tem sido um desafio pelos pesquisadores dessa área durante os últimos anos. Neste trabalho, apresentaremos uma expressão para impedância acústica derivada de um coeficiente de reflexão de ondas $\mathrm{P}$ rápidas em meios poroelásticos, considerando a incidência normal das ondas. A aplicação da metodologia desenvolvida ponto a ponto em dados de perfilagem mostra uma relação direta entre os módulos elásticos do meio com a porosidade. Também se pode apresentar por meio de uma análise da metodologia aplicada que meios elásticos podem ser considerados uma aproximação de meios poroelásticos quando satisfeitas algumas condições.

\section{Introdução}

A teoria da poroelasticidade de Biot, apesar de possuir mais de meio século desde sua formulação, continua sendo uma das melhores opções para se descrever o ambiente sedimentar onde se inserem reservatórios de óleo e gás, isto é, meios porosos saturados por fluidos. Dentre seus principais trabalhos, Biot descreveu um modelo para a relação constitutiva em meios poroelásticos incluindo a poro pressão (Biot,1941), e tratou a teoria da propagação das ondas elásticas em sólidos porosos saturados por fluidos, considerando baixas e altas frequências de investigação (Biot 1956a, 1956b). Outros trabalhos foram, e continuam sendo, produzidos tendo como ideia central a poroelasticidade.

A partir da aplicação das condições de contorno adequadas Dennemann (2002) deduziu os coeficientes de reflexão para ondas se propagando de um meio líquido para um poroelástico, e demonstrou complexidade desse tipo de estimativa dada a dependência da frequência de investigação. Em trabalho análogo, porém, considerando dois meios poroelásticos com características diferentes separados por uma interface, Gurevich (2004) determinou os coeficientes de reflexão e transmissão para uma onda $P$ incidindo normalmente na interface. Como resultado obteve dois coeficientes para a convertida onda $P$ rápida e dois para a lenta. Quintal (2011) fez um estudo qualitativo sobre o impacto da saturação por fluido nos coeficientes de reflexão em camadas poroelásticas. A atenuação sísmica e a atenuação de velocidades foram consideradas utilizando o modelo apresentado em White (1975) para onda induzida pelo fluxo do fluido.

Aos estudos e aprimoramentos dos coeficientes de reflexão, são dados muita atenção, tomada sua importância na construção das seções empilhadas conforme mostra a literatura. Porém nem sempre é possível, ou financeiramente inviável realizar a aquisição sísmica para construção de sismogramas. Neste cenário são construídos sismogramas sintéticos a partir da estimativa da impedância acústica (near-offsets) ou impedância elástica (middle-offsets) apresentada em Connolly (1999). Neste trabalho, foram realizadas uma série de aproximações nos coeficientes de reflexão para incidência normal das ondas convertidas $P$ rápidas, apresentados por Gurevich (2004), para encontrar contrastes relativos dos parâmetros do meio e obter uma expressão analítica para estimativa da impedância acústica, incorporada das propriedades poroelásticas.

A generalização da metodologia da impedância acústica para meios poroelásticos torna sua aplicabilidade mais fidedigna por introduzir fatores inerentes ao meio, até então não levados consideração. Futuramente o traço da impedância acústica aplicada em meios poroelásticos para construção de sismogramas sintéticos poderá revelar feições e tendências das bacias sedimentares até então não percebidas.

\section{Metodologia}

Em meios poroelásticos, após a incidência normal de uma onda $\mathrm{P}$ em uma interface separando duas camadas com parâmetros petrofísicos distintos, é possível perceber além da onda $P$ convencional, uma segunda onda $\mathrm{P}$ com velocidade muito inferior a primeira. Em Biot (1956a), a existência desse segundo tipo é explicada utilizando o conceito de movimentação relativa entre o fluido e a matriz porosa. Esse segundo tipo de onda é chamada onda P lenta.

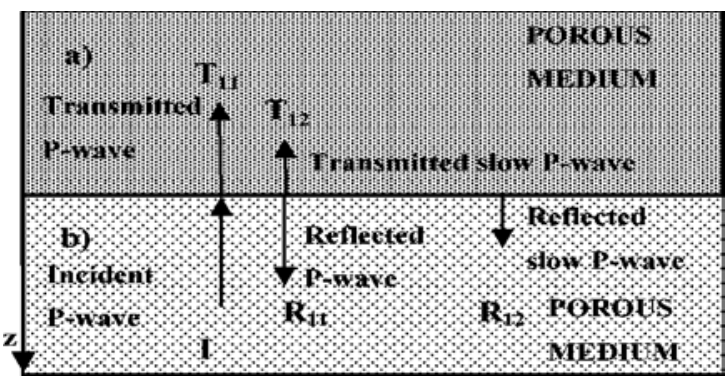

Figura(1): Ondas convertidas a partir da incidência de uma onda $P$ na interface que separa os meios a e b (Figura retirada de Gurevich (2004)). 
Em Gurevich (2004) apresenta-se uma expressão analítica para os coeficientes de reflexão dessas ondas, considerando-se incidência normal. Essas expressões foram obtidas utilizando-se as seguintes condições de contorno:

$$
\begin{aligned}
& u_{a}=u_{b}, \\
& w_{a}=w_{b}, \\
& \tau_{z z}^{a}=\tau_{z z}^{b}, \\
& P_{a}=P_{b} .
\end{aligned}
$$

Essas condições de contorno representam continuidade do deslocamento de partículas $u$, do deslocamento relativo sólido-fluido $w$, tensão normal $\tau$, e campo de pressões $P$. O coeficiente de reflexão para as ondas convertidas $\mathrm{P}$ do tipo rápidas, é determinado conforme a seguinte expressão:

$$
R=\frac{\rho_{b} v_{b}-(1-X) \rho_{a} v_{a}}{\rho_{b} v_{b}+(1+X) \rho_{a} v_{a}}
$$

Assim como o modelo convencional, isto é, em meios elásticos, o coeficiente de reflexão em meios poroelásticos também depende da densidade $\rho$ e da velocidade de propagação da onda $\mathrm{P}$ nos meios $a$ e $b$. O termo $X$ introduz na teoria a informação da poroelasticidade do meio. Esse termo possui dependência indireta dos módulos elásticos do meio, da porosidade e dos números de onda das ondas $\mathrm{P}$ rápida $\mathrm{e}$ lenta que se propagam nos meios $a$ e $b$.

A partir da expansão do termo $X$ e de algumas aproximações, é possível reescrever a expressão (2) em função de contrastes relativos de algumas propriedades do meio. Utilizando metodologia semelhante a apresentada em Connolly (1999) para formulação da impedância elástica a partir da equação linearizada de Zoeppritz, determinamos uma função denominada impedância acústica, acrescida da informação da poroelasticidade do meio incorporada pelas constantes poroelásticas. Essa nova impedância é dada pela seguinte expressão:

$$
A I_{\text {poro }}=\rho v \frac{H}{C} .
$$

Os termos $H$ e $C$ são duas das constantes poroelásticas presentes na teoria apresentada por Biot, e dependem dos módulos de compressão do fluido, do grão constituinte e da matriz rochosa, e dos módulos de cisalhamento do grão e da matriz rochosa, além da porosidade da rocha.
No intuito de avaliar a aplicabilidade da metodologia desenvolvida em ambientes sedimentares, utilizamos a expressão (3) em profundidade, a partir de dados de perfilagem, para estimar um perfil de impedância acústica. Os dados de perfilagem utilizados contam com medidas de densidade, porosidade neutrônica, resistividade, vagarosidade de ondas $P$ e $S$, e raios gama. Ao todo são 701 medidas realizadas a cada $20 \mathrm{~cm}$ a partir da profundidade de $2750 \mathrm{~m}$. As estimativas das constantes poroelásticas $H$ e $C$ foram realizadas adotando como valores para os módulos elásticos de compressão $K_{g}$ e cisalhamento $\mu$ os de grãos arenosos, e o fluido saturante foi considerado como sendo água $\left(K_{f}\right)$, conforme a tabela-1.

Tabela (1) - Valores adotados para os módulos elásticos.

\begin{tabular}{|c|c|c|}
\hline$K_{q}$ (GPa) & $\mu$ (GPa) & $K_{f}$ (GPa) \\
\hline 40.00 & 3.40 & 2.22 \\
\hline
\end{tabular}

O módulo de compressão da rocha pôde ser obtido a partir dos perfis de vagarosidades e densidades pela teoria elástica convencional conforme a equação (4).

$$
K=\rho\left(V_{p}^{2}+4 / 3 V_{s}^{2}\right)
$$

O resultado obtido é apresentado na figura (1).

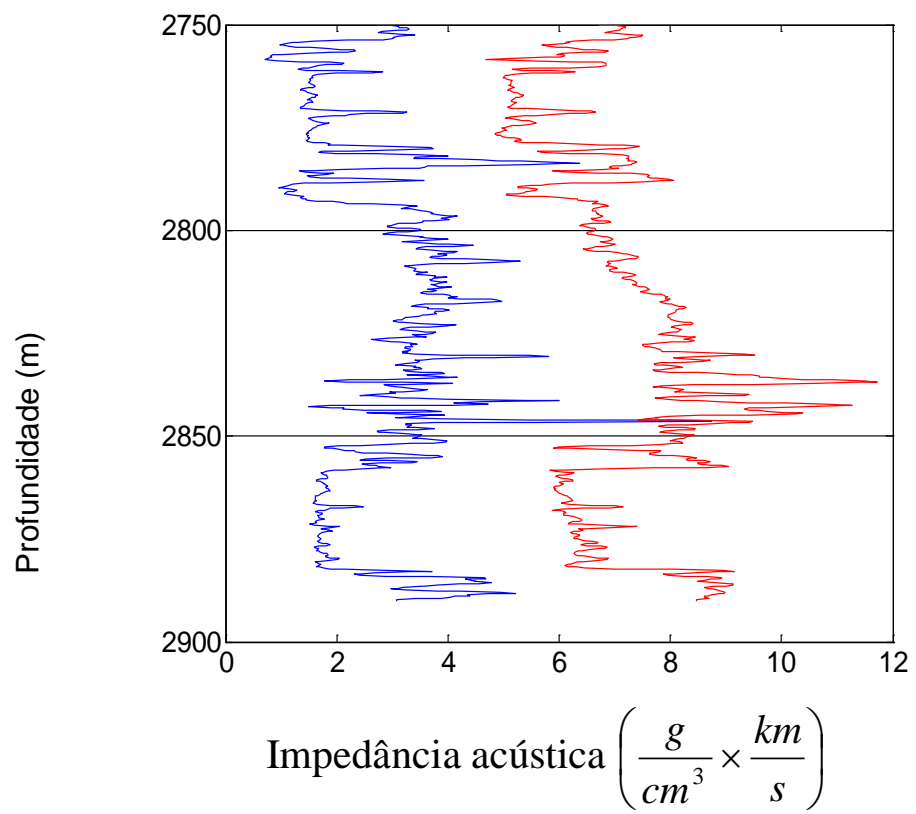

Figura(2): Em vermelho a impedância acústica obtida considerando o meio como sendo elástico. Em azul a impedância acústica assumindo a inclusão dos parâmetros poroelásticos.

\section{Resultados}


A expressão (3) se reduz a impedância acústica convencional $(A I=\rho v)$ quando a constante poroelástica $H$ é igual a constante poroelástica $C$. Igualando as constantes e escolhendo a porosidade como parâmetro de controle para satisfazer a igualdade, obtemos como resultado a seguinte expressão:

$$
\phi=\frac{-4 K_{f} \sigma \mu}{3(K+4 / 3 \mu)\left(K_{g}-K_{f}\right)},
$$

sendo o termo $\sigma$ dado por:

$$
\sigma=1-\frac{K}{K_{g}}
$$

Quando realizada a estimativa das constantes poroelásticas aplicando-se o vínculo estabelecido pela expressão (4), os perfis de impedância, considerando-se o meio como elástico e poroelástico, reduzem-se a mesma curva, conforme imposto. A porosidade que foi estimada para ser utilizada como parâmetro de controle para a convergência da impedância acústica aplicada em meios poroelásticos para meios elásticos apresenta a distribuição mostrada abaixo.

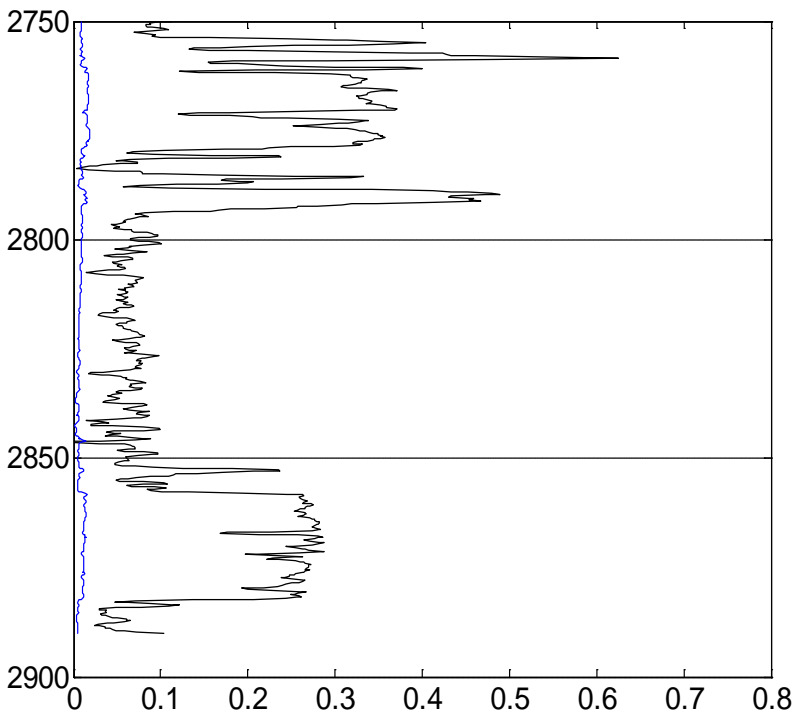

\section{Porosidade}

Figura(3): Em preto a porosidade efetiva real do pacote sedimentar, e em azul a porosidade utilizada como parâmetro de controle.

A figura (3) apresenta dois perfis de porosidade para comparação: o de porosidade efetiva real obtida pelo perfil de densidades e corrigida pelo volume de argila, e o de porosidade utilizada como parâmetro de controle para que as constantes poroelásticas $H$ e $C$ sejam iguais. Pelo perfil de porosidade efetiva real, é possível perceber que dentro do intervalo sedimentar avaliado se inserem duas camadas de rochas reservatórios com porosidades médias de $33 \%$ e $27 \%$, enquanto que o perfil de porosidade usada como parâmetro de controle tende a zero.

\section{Discussão e Conclusões}

Apesar da aplicação de diferentes metodologias para estimativa da impedância acústica, pode-se perceber pela figura (2), que o perfil de impedância acústica considerando a inclusão dos parâmetros da poroelasticidade (curva em azul), segue uma tendência muito parecida com a do perfil de impedância acústica construída utilizando a teoria convencional (curva em vermelho), a menos de uma fase. Ou seja, meios poroelásticos apresentam uma resistência menor a movimentação das suas partículas quando comparados com meios sólidos (elásticos). Logo, realizada a construção de sismogramas sintéticos utilizando a teoria convencional da impedância acústica ou com a inclusão das propriedades poroelásticas, os aspectos estruturais interpretados não iriam apresentar grandes disparidades. A menos da acentuação do intervalo de reservatório, que pelo perfil de impedância considerando o meio como poroelástico fica mais destacado.

Conforme discutido, a condição para que a impedância acústica em meios poroelásticos se reduzisse a impedância em meios elásticos, é dada pela equação (4). Observando a figura (3), percebe-se que a porosidade estimada assume valores que tendem a zero, ou seja, o de rocha sólida. Analisando a equação (4), vemos que nenhum dos módulos elásticos é nulo e a única condição possível para que a porosidade tenda a zero, é que a constante $\sigma$ também tenda a zero. De acordo com a expressão (5), $\sigma$ tende a zero apenas quando é satisfeita a seguinte condição:

$$
K \approx K_{g}
$$

Considerar que o módulo de compressão da rocha coincide com o módulo de compressão do grão constituinte, implica que o arcabouço rochoso não possui poros com potencial para armazenamento e escoamento de fluidos. Nesse caso a poro pressão é nula e a impedância acústica em meios poroelásticos se reduz a impedância acústica em meios elásticos.

\section{Agradecimentos}

José Sampaio de Oliveira a CAPES pelo suporte financeiro ao seu doutorado e ao Departamento de Pósgraduação em geofísica (DpPG) e professores do Observatório Nacional. 


\section{Referências}

Quintal B., Stefan M. Schmalholz, and Yuri Y. Podladchikov, 2011, Impact of fluid saturation on the reflection coefficient of a poroelastic layer. Geophysics, 76, 1-12.

Biot, M. A., 1941, General theory of three-dimensional consolidation: Journal of applied physics, Vol. 12, No. 2, pp. 155-164.

Biot, M. A., 1956a, Theory of propagation of elastic waves in fluid saturated porous solid, I - Low frequency range: J. Acoust. Soc. Am., 28, 168-178.

Biot, M. A., 1956b, Theory of propagation of elastic waves in fluid saturated porous solid, I - Higher frequency range: J. Acoust. Soc. Am., 28, 179-191.

Connolly P., 1999. The Leading Edge, April, v. 18, p. 438.

Denneman, A. I. M., Drijkoningen G. G., Smeulders D. M. J., and Wapenaar K., 2002, Reflection and transmission of waves at a fluid/porous-medium interface: Geophysics, 67, 282-291.

Gurevich, B., Ciz, R. and Denneman, 2004, Simple expressions for normal incidence reflection coefficients from an interface between fluid-saturated porous materials. Geophysics, 69: 1372-1377.

White, J. E., 1975, Computed seismic speeds and attenuation in rocks with partial gas saturation: Geophysics, 40, no. 2, 224-232. 